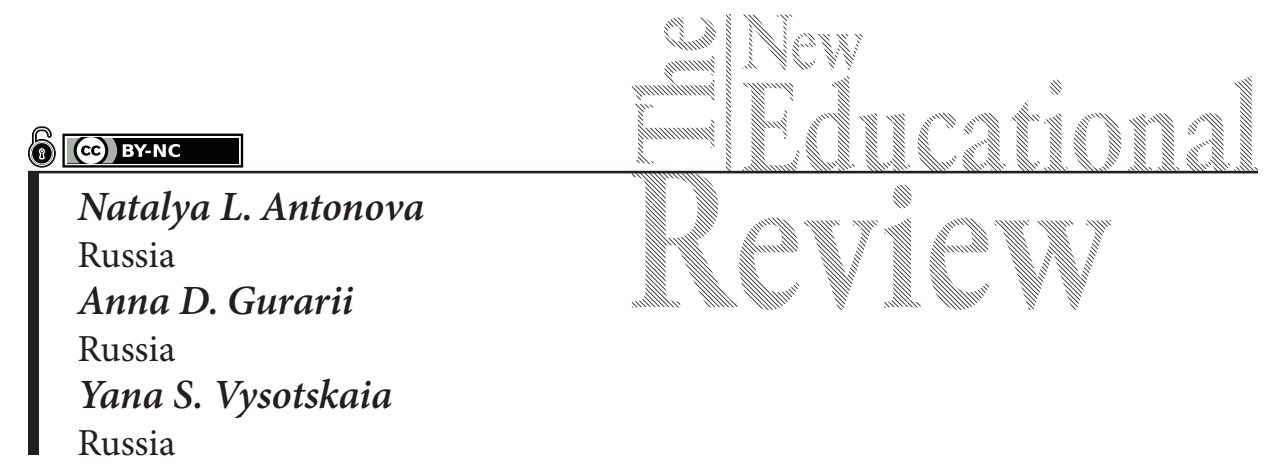

\title{
Short-Term Student Mobility: Motivation, Expectation and Barriers
}

DOI: 10.15804/tner.2020.59.1.10

\begin{abstract}
The article analyses short-term student mobility. In the context of internationalisation of higher education and the development of the global market of educational services universities develop and implement short-term programmes of student mobility in order to recruit international students. These programmes are less restricted than full time programmes, which allows them to meet the needs and expectations of students. International experience gained as a result gives them the opportunity to choose their path in postgraduate education in institutions abroad. A questionnaire survey of the Chinese students participating in the short-term student mobility programmes $(n=31)$ is reported. In addition, a number of interviews with the staff whose work is connected with teaching overseas students $(n=5)$ was conducted in 2019 . The findings of this research may demonstrate that Chinese students intend to become familiar with an additional set of common cultural competences. In other words, their interest in Russia, its history, culture, traditions and customs is becoming a strong motivation in choosing a university and a short-term educational programme. It could be the case that low language proficiency, bureaucracy, (namely, difficulties in acquiring the necessary paperwork and being accommodated in a hall of residence) become hurdles on the way to completing such a programme successfully. While developing programmes, host universities should be guided by common cultural competences in order to promote further development of short-term student mobility.
\end{abstract}

Key words: short-term student mobility, short-term educational programmes, international students, internationalisation of the education, higher education, university 


\section{Introduction}

In the era of globalisation questions about the internationalisation of higher education have been raised among both the academic community and the academic administration. The global market of educational services, at which universities present international academic mobility programmes, thus showing their status, prestige and the number of international students, for all intents and purposes dictates its terms, defining the structure, factors, mechanisms and tools of internationalisation. The traditional understanding of internationalisation, given by Knight (2012, pp. 4-5) as the process of inclusion of intercultural and international dimensions in the aims and functions of higher education, is being redefined and modified today (Teichler, 2017, pp. 177-216). This is connected with the commercialization of education, the "race" for ratings, the transformation of knowledge from a public good into a resource.

National systems of higher education develop in accordance with the vectors of globalisation, one of which is organizing short-term and long-term international educational programmes. What is being discussed is that universities are actively trying to attract international students, responding to their request to be educated abroad. The experience of studying in another country furthers the personal and academic development of students, helping them grow in global and cultural consciousness, which, in the XXI century, is becoming an increasingly important institutional goal (Gaia, 2015, pp. 21-31).

Universities all over the world are aiming to develop and implement educational projects which give the students of the XXI century the opportunity to navigate the global information space freely, to become full-fledged participants of international processes, at the same time acting in the interests of their own countries (Knight, 2004, pp. 5-31). Integration of students into the global student community by means of overcoming national isolation and gaining the experience of international cooperation is a major task of international educational programmes. New competences that develop in the process of collaborative research, and the experience of collaboration itself, lead to new social and professional opportunities, determine the position of a student as a professional-to-be within the system of global connections and on the global labour market (Shields, 2003, pp. 609-636).

The global numbers of international students in programmes of higher education, according to data published by OECD (Education at a Glance 2017: OECD Indicators, 2017), have increased dramatically over the lifetime of one generation - from 0.8 million at the end of the 1970s to 4.6 million in 2015. Students from 
Asia comprise the largest group of international students at all levels of higher education, with 612,000 out of 1.56 million of students studying in 2015 being from China. Such countries as the USA, Australia and the UK attract the largest proportion of Asian students (44\%, 16\% and 15\% respectively).

By attracting foreign students, a university as a social organization becomes a 'conductor' for a student's realization of a chosen educational trajectory. At the same time, in the current research not enough attention is being paid to the question of short-term student mobility, its attractiveness, and the demand for it among students.

\section{Materials and Methods}

According to the documents that regulate the implementation of the Bologna agreements (Bologna Process Implementation Report, 2015) there are two main forms of international academic mobility. Degree mobility can be defined as enrolment in a foreign university with the aim of completing a full degree, while credit mobility means completing a limited period of studying abroad within the framework of on-going studies at a home institution. A crucial moment here is the necessity to make the definition of short-term international student mobility wider, as modern conditions demand, not limiting it merely to studying in a foreign university for the period of one or two terms. Apart from credit mobility, other forms of short-term student mobility can be observed, among them: winter and summer schools, work placements, internships, familiarization trips, and language courses, which in the current conditions are becoming more and more popular with young people in the academic environment. Less strict regulation and increased flexibility that make quick and efficient response to the changing needs of the students possible are some of the advantages of short-term programmes.

Modern universities are aiming to develop international thinking in their students by offering their own academic mobility programmes and sending their students abroad. The main goal of short-term student mobility is the familiarization of participants with the international community (Slotkin, Durie, \& Eisenberg, 2012, pp. 163-173). The international experience gained enables students to correct their educational trajectory, determine the interest and desire for further education, for instance, in post-graduate programmes in universities beyond the borders of their own countries. For instance, Lewis and Niesenbaum (2005, pp. 251-264) demonstrated that more than half of the participants of short-term student mobility programmes had chosen to study abroad again. Dwyer considers 
that this is an indicator of the successful academic work of a student (2004, pp. 151-163).

Short-term student mobility promotes cross-cultural sensitivity and serves as a factor increasing interest in the language of the host society (Martinsen, 2008, pp. 504-530). Mastering the language, in its essence, means entering a new, unfamiliar lifestyle, conceptualizing cultural differences, reproducing the norms, notions, practices, and standards of behaviour of foreign-language societies (Schwald, 2012, pp. 44-55). Along with this, however, integration in the foreign language environment might cause tension but, as McKeown (2009) claims, it also stimulates the personal growth of the students, together with helping them self-actualise, find and assert their place in the world. Not only do the students start to understand another culture in the process of intercultural immersion, but they also learn to understand themselves, which furthers self-development and helps them unlock their adaptation potential.

The development of short-term student mobility may indicate the complexity of institutional bonds in the global educational space, together with the coming into being and development of new organizational structures, which function within universities and are oriented to attracting international students, the institution must pay attention to actualisation of the students' educational needs and to the promotion of short-term educational projects. Researchers note the tendency for regionalization of higher education, in other words, the orientation to neighbouring countries for collaboration (Yonezawa, Kitamura, \& Kuroda, 2014).

The main goal of the research conducted in January 2019 was the analysis of opinions and beliefs of Chinese students on short-term mobility programmes at Ural Federal University (UrFU). During this time the university offered such programmes as sports, gamification, and cross-cultural communication in the modern Russian reality.

The following goals were set: firstly, to determine students' motivation for enrolling on a short-term educational programme; secondly, to estimate the expectations the foreign students had in relation to the programme; thirdly, to ascertain the difficulties the students faced in the process of studying. The number of those surveyed totaled 31 . The questionnaire, distributed after the classes, was completed in 10 minutes on average. The gender ratio of participants, three quarters of whom were aged 21 to 23, was 10 females to 21 males. Every third surveyed was a 4 -year undergraduate student.

It is necessary to draw attention to the fact that in the process of devising the methodological strategy of the research authors were guided by the notion that the students acquiring education in UrFU experience difficulties understanding 
the Russian language (Merenkov, \& Antonova, 2015, pp. 122-132), which stops them accessing it as the basic mechanism of human interaction (Guzikova, 2019, pp. 114-123). For this reason, the questionnaire was translated into Chinese, which afforded us the opportunity to eliminate the language barrier and acquire reliable information. The choice of a questionnaire as a means of gathering information for such a small group of survey participants was dictated by the language barrier, as in order to conduct interviews the authors would have had to engage Chinese-speaking professionals.

The tool of the research comprised 10 questions, including open-ended (2), semi-closed (3) and closed-ended (5). As a result, students were provided with the opportunity to express their own opinions on questions of motivation behind the choice of the short-term educational programme, the hurdles they encountered while studying and the role of academic mobility in their plans for the future. The data obtained was processed with the help of the sociological and marketing information analysis software Vortex (version 10).

To ensure deeper understanding of aspects of implementation of short-term educational programmes at the university and to determine the main obstacles Chinese students face in acquiring education, semi-structured interviews were carried out with those faculty members and employees of UrFU who work with students from China. The interview guide consisted of 5 questions, with the interviews lasting for approximately 30 minutes. Five females who had worked at university for periods from 7 to 17 years were interviewed in their time off, after which the interviews were transcribed, the answers collated and grouped in accordance with the aims of the research.

\section{Results and Discussion}

The leading positions in the motivational structure of the arrival to UrFU were taken by such motives as desire to see Russia, interest in the programme and its low cost. Notably, as the results of the survey show, only every tenth student did not possess any information about Russia before arrival. First of all, Chinese students educated themselves on the economic and political situations, with every third of those surveyed being informed about Russia's history, and every sixth - about its art and culture. The research revealed insufficient socio-cultural background information among Chinese students, which tends to lead to a prolonged period of adaptation and decreases the level of success in communication with members of the host society. 
The fact of coming to another country within the framework of academic mobility evokes hardship in the everyday life of a student. Only every fifth surveyed student remarked that they possessed information about the rules and social norms of behaviour in the street, in shops, cafes and other public places of a large Russian city.

Speaking about the short-term educational programme chosen by Chinese students, the survey indicated a high level of awareness. For instance, more than half of the respondents had acquainted themselves with its contents before coming to Russia, which means that they had made an informed choice.

The low cost of higher education in Russian universities was emphasized by the experts. "The cost of education, in comparison with the foreign institutions, is negligible ..." (female, 7 years' work experience). To illustrate, the cost of a shortterm educational programme varies from 500 to 1000 USD.

Practically every surveyed student stated that their expectations of studying at UrFU were met. Just one respondent indicated dissatisfaction with the choice of the vector of short-term student mobility. Interestingly, while only three students answered a definitive yes to the question of whether the reality matched their expectations (the others choosing the "more likely yes than no" option), three quarters of those surveyed plan to recommend the short-term educational programme to their friends and relatives. As one of the experts stated during interview, “... Chinese students often make a choice in favour of the higher education institution with which they have links and connections, which one of their family members, or acquaintances have attended..." (female, 17 years' work experience).

At the same time, the data collected reveals several trouble spots. On the one hand, the short-term educational programmes offered by the university fulfil the needs of the Chinese students, which is supported by their desire to recommend them upon returning to their homeland. Nevertheless, it is necessary for the university as a host to solve a number of issues in problematic areas that hinder the meeting of the needs of student migrants. Among such issues, which, perhaps, might be alleviated at the managerial level, the respondents named lack of organised leisure activities, subpar quality of accommodation and the ordeal of obtaining required paperwork. The problem of the growing level of bureaucracy in education in Russia was also raised by the experts, one of whom remarked “...yes, there is such problem. A student has to knock on many doors to achieve results in solving everyday issues. ...quite often students choose to solve problems via the Chinese consulate: they were not given something at some stage, but they clearly understand that they can get it via the consulate..." (female, 17 years' work experience). 
Low language proficiency and lack of understanding of the norms and customs of everyday life were mentioned among other obstacles that decrease the effectiveness and hinder success in completing educational programmes. The language barrier is the major issue in the inclusion of the foreign students in the process of education, and the lack of grasp of the culture of the host society and its traditions further hinders language acquisition.

What is the role of short-term student mobility in the life of students from China? The findings of the survey showed that participation in the programme was conducive to the broadening of their horizons, by giving them access to information about the Russian culture and the life of the inhabitants of a large industrial city. Every eighth respondent claims to have improved their communication skills, while every tenth considers the knowledge acquired as a personal asset that will be instrumental in them getting a prestigious job. According to the assessment of the experts, for almost every Chinese student the educational programme, no matter how short it is, serves as an indicator of status "...coming to Russia to study is in itself prestigious." (female, 7 years' work experience).

Looking at higher education through the lens of the competency approach, we can observe the need foreign students have for obtaining, first of all, common cultural competences within the framework of short-term student mobility. This suggests that within such frameworks both specialised disciplines and subjects oriented to the wider scope of general education should be represented. Furthermore, immersion in the foreign language environment will be more effective in the context of acquiring communicative competences on condition that the students' need for better leisure activities is taken into account by the developers of shortterm student mobility programmes.

\section{Conclusions}

The study conducted has led authors to the following conclusions. Short-term student mobility of the Chinese students is connected, in the first place, with the mastering of additional common cultural competences. The need to acquire information about Russia plays a leading role in the structure of motivation for coming to the country to study. Besides this, the students name the broadening of their horizons and the knowledge gained about the culture of the host country among the results of receiving such education.

Barriers observed spoil the successful outcome of a visit to Russia and the participation in short-term educational programmes. Firstly, there are the obstacles 
that a student is capable of surmounting on their own, such as the low level of proficiency in Russian and the lack of information about the cultural norms that characterise the host society. Secondly, there are some organisational, systemic hurdles that could be overcome by introducing corrections to the management of the educational projects aimed at international students. In this case we are talking about reducing bureaucracy related to paperwork, accommodation et cetera, as well as including organised leisure activities for foreign students.

For a university as a whole, inviting international students to participate in short-term educational programmes is instrumental in achieving a certain number of strategic goals, the inclusion into the global educational space being one. Making such a project happen provides new opportunities for the involvement of students in postgraduate studies. Collaboration with the leading businesses and institutions in the area will increase the university's recognition and appeal for future academic mobility. The faculty's worth as an asset will grow as they develop their English skills by presenting lectures in English in their given subjects. The interdisciplinary projects carried out within the framework of short-term educational programmes will promote the understanding of common cultural competences.

The results of the conducted research, in our opinion, reveal a number of prospective directions in which it is possible to study short-term student mobility further. The development of the global market is posing a challenge to Russian universities. In light of this fact, studying existing marketing strategies of universities, analysing the institutional cooperation of the players on the market, and defining pressing educational needs, not only of the students but of the faculty as well, all appear important.

\section{Acknowledgements}

This research was supported by a Russian Science Foundation grant to the Ural Federal University (№ 18-18-00236). The authors are grateful to Ekaterina S. Purgina for the organization of the translation of the questionnaire from Russian to Mandarin Chinese.

\section{References}

Dwyer, M.M. (2004). More is better: the impact of study abroad program duration. Frontiers: The Interdisciplinary Journal of Study Abroad, 10, 151-163.

Gaia, A.C. (2015). Short-term faculty-led study abroad programs enhance cultural 
exchange and self-awareness. The International Education Journal: Comparative Perspectives, 14(1), 21-31.

Guzikova, M.O. (2019). Multilingualism in motion: evolution of the phenomenon. Tomsk State University Journal of Philosophy, Sociology and Political Science, 49, 114-123. DOI: 10.17223/1998863X/49/12.

Knight, J. (2004). Internationalization remodeled: Definitions, approaches, and rationales. Journal of Studies in International Education, 8(1), 5-31. DOI: 10.1177/1028315303260832.

Knight, J. (2012). Five Truths about Internationalization. International Higher Education, 69, 4-5. doi: 10.6017/ihe.2012.69.8644.

Lewis, T.L., \& Niesenbaum, R.A. (2005). Extending the stay: Using community-based research and service learning to enhance short-term study abroad. Journal of Studies in International Education, 9, 251-264. DOI: 10.1177/1028315305277682.

Martinsen, R.A. (2008). Short-term study abroad: predicting changes in oral skills. Foreign Language Annals, 43(3), 504-530. DOI: 10.1111/j.1944-9720.2010.01095.x.

McKeown, J.S. (2009). The First Time Effect: The Impact of Study Abroad on College Student Intellectual Development. Albany, NY: State University of New York Press.

Merenkov, A., \& Antonova, N. (2015). Problems of social adaptation of international students in Russia. New Educational Review, 41(3), 122-132. DOI: 10.15804/ tner.2015.41.3.10.

OECD (2017). Education at a Glance: OECD Indicators. Retrieved 23/08/2019, from https:// www.hm.ee/sites/default/files/eag2017_eng.pdf.

Schwald, R. (2012). Toward a new practice of internationalization: a case study on a shortterm study abroad program at European institutions of higher education. Review of European Studies, 4(2), 44-55. DOI: 10.5539/res.v4n2p44.

Shields, R. (2003). Globalization and International Student Mobility: A Network Analysis. Comparative Education Review, 57(4), 609-636. DOI: 10.1086/671752.

Slotkin, M.H., Durie, C.J. \& Eisenberg, J.R. (2012). The benefits of short-term study abroad as blended learning experience. Journal of International Education in Business, 4(2), 163-173. DOI: 10.1108/18363261211281762.

Teichler, U. (2017). Internationalisation Trends in Higher Education and the Changing Role of International Student Mobility. Journal of international Mobility, 5(1), 177-216. DOI: $10.3917 /$ jim.005.0179.

The European Higher Education Area in 2015. Bologna Process Implementation Report. Retrieved 23/08/2019, from www.ehea.info/media.ehea.info/file/2015_Yerevan/73/3/2015_Implementation_report_20.05.2015_613733.pdf.

Yonezawa, A., Kitamura, Y., \& Kuroda, K. (eds.). (2014). Emerging International Dimensions in East Asian Higher Education. Dordrecht: Springer. 